\title{
Swales Discourse Space Research and the Correlation Analysis of College Students' English Writing
}

\author{
Deng Hongxia ${ }^{1}$ \\ ${ }^{1}$ College of Foreign Languages, Hunan University, Changsha, Hunan, 410000
}

Keywords: college students’ English writing; Swales; discourse space; correlation analysis

\begin{abstract}
This paper first elaborates on the theory and method of genre analysis and Swales' creation of discourse space model, and uses the English writing submitted in the English writing course of 60 college students in a university as the experimental data for quantitative analysis. The relationship between Swales' creation of discourse space research and college students' English writing is of great help to improve college students 'ability of writing English and control the whole length of college students' English writing.
\end{abstract}

\section{Introduction}

In recent years, with the socio-economic development in our country, the reform and opening up have achieved very far-reaching results both in breadth and depth, and all walks of life have enjoyed a flourishing and prosperous development. At the economic level, as one of the important members of the WTO, China's economy has gradually become an important part of the world economic system. As China's economy merges with the world economy and deepens its internationalization, the international trade activities between the two countries are increasingly frequent. As a universal language, English plays an important role in foreign trade and its importance is also recognized by the world trade [1]. At different levels and angles of politics, economy and culture, as one of the major international languages in the world, English is displaying its long history and culture with its unique grammatical form, highlighting its role as a modern cultural exchange between China and the West and the world Importance of information dissemination tools in development [2]. Undergraduates are the elite collective of the times, bearing the important mission of carrying forward and inheriting Chinese traditional culture on their shoulders. In today's rapidly evolving global village of information, the students are encouraged to enhance their understanding of the glorious history and culture of China and strengthen the cooperation between China and the world in the economy, Politics, culture, science and technology, and narrowing the gap between China and the developed countries in the West are important goals for the cultivation of contemporary college students [3]. College students' writing ability in English is a basic ability that college students should possess. English writing skills are considered in many English skills. College students first need to master English vocabulary and grammar effectively. On the basis of efficient internalization of English language knowledge, Understand, master English writing skills and writing strategies, in order to truly "understandable output" to achieve the goal of improving college students' English writing ability and writing skills. At this stage, domestic and foreign scholars have infiltrated the theory and method of genre analysis into the field of linguistics, created the research space discourse with swales, split the English article into chapters and analyzed chapter by chapter to enhance the writing ability of English writers, the comprehensive analysis of English writing and the full range of ability to enhance, but also the lack of college students English writing as the research object, the quantitative analysis of swales to create a research space text and college students' English writing data and experimental support [4].

\section{Genre Analysis Theory and Method}

Genre refers abstractly to the type and style of artwork, and schools of different definitions of genre have different views and opinions. For example, Australia's JR Martin argues that genre is a 
step-by-step approach to a speaker as a cultural member. There is a certain set of goals, purposeful behavior [5]. While John M. Swale of the University of Michigan in the United States believes that genre is a type of communicative event. If a group of communicative events have the same communicative purpose, they may belong to the same genre even though their prototypes are different and the articles are different [ 6], this definition of the genre gradually derived from the famous Swales school. Although there are differences in the definition of genres between the two schools, their views and opinions are highly consistent in the following two aspects: one or two schools of scholars study and analyze genres from the perspective of linguistics. Both schools agree that there is a close relationship between the semantic function of the schema structure component of the genre and how the lexical grammar is implemented.

Genre analysis aims at analyzing how people express themselves in actual social and interpersonal communication to explore how people can skillfully use language power and language strategies to achieve their ultimate goal of social communication. Genre is a type of communicative event, and the genre analysis methods and modes adopted by different genres should be different. For example, in 1983, Hoey analyzed the "problem-solvability" genre, believing that the genre analysis mode should be summarized concisely for the scene - the problem - the reaction - the evaluation / the result [7], this kind of genre analysis pattern the suitable discourse including the scientific research thesis, the experiment report and so on the extremely specialized and research genre, in the natural science. For example, the thesis writers need to elaborate on the writing background first, through the concise and sonorous language to bring the article's perspective from a more macro background to the relatively narrow and targeted natural sciences in order to draw the essay. The object of study and the scientific problem to be solved, and then design the corresponding experimental scheme according to the scientific problem, and assist the experimental or analytical method to qualitatively or quantitatively evaluate the experimental results to reach the goal of solving the scientific problems raised in the thesis. In recent years, with the continuous development of the theories and methods of various disciplines, the poor multidisciplinary and integration become important channels and driving forces for the development of disciplines, genre analysis is no longer limited to linguistic analysis of style and discourse, more is the introduction of sociology and psychology theory and method, the target genre is not limited to more professional scientific papers or research reports, and more to expand the nature of narrative nature of the exchange and communication genre, the clever use of sociology and psychology learn from methods applied to linguistic analysis, the language of discourse embodied in specific human psychological behavior and social phenomena in order to view the language from different academic perspectives characteristics, the sociality and normativity of discourse, the construction strategy and cognitive structure of discourse, and to explore how communicators can use their discourse and language strategies to fulfill their idealistic social communicative goals.

\section{Swales' Discourse Space Research Model}

John M. Swale of the University of Michigan in the United States is a representative of the Swales school. Through the investigation and research of various master's thesis and master's thesis in the natural sciences and humanities, it is found that highly specialized academic papers have a high degree of consistency with the organizational structure, and believe that this high degree of consistency is to ensure that academic papers as the essence of academic achievements, for different disciplines of researchers and scholars to provide universal academic exchanges and academic exploration of the medium of understanding, this universal medium can become the academic mode of writing should follow the genre. In 1990, Professor John M. Swale first proposed the concept and related theories of creating a research space model [8] in his book entitled Genre Analysis, to create space. The discourse model highly summarizes the introductory part writing style of the specialized or social academic dissertations. The introduction part of the thesis is divided into three parts. Through the three step-by-step structure, it can clearly and concisely. The author of the academic thesis to express the point of view and its true goal of academic communication into the essay, to facilitate readers of academic papers accurate grasp of the research background, research 
significance and research innovation. The three steps of Swales' creation of research space discourse include: First, the author reviews the research background of the dissertation to introduce the reader into the research field of the dissertation. The research background includes the social background and current academic research both at home and abroad. As well as the evolution of research methods to index the research results, highlight the importance and significance of the scientific issues studied in academic papers; second, based on the analysis of the academic research achievements at home and abroad as well as the progress of research, pointed out that existing research exists in order to extend and conclude the research problems of academic dissertations, which can vaguely emphasize the importance of the research of this dissertation for the research field. Thirdly, the research content and research methods of academic dissertations are elaborated. The contents of this research and research methods should be carried out closely around the research questions proposed in Step Two, with a high degree of rationality, scientificity and feasibility. The results of qualitative or quantitative research will be briefed to reveal the innovative points and new findings of academic papers [9]. Swales' creation of a text space for research space provides an essay writing template similar to that of ancient China, but far less than the rigidity and solidification of the essay writing. On the one hand, Swales maintains a high degree of content flexibility and Vividness, and on the other hand, it provides a standardized reference template for the writing of academic essays. It improves the readability and comprehensibility of academic essays from the discourse structure, and facilitates the academic essay as a highly condensed text of scientific research. Sexual summaries effectively convey scholars' scientific research ideas and academic findings, and promote professional academic exchanges and exchange of ideas.

\section{Data Collection and Correlation Analysis}

In this paper, 60 college students in a university English writing course written in English writing as experimental data used to quantitative analysis of swales to create a research space discourse and college students English writing correlation sample data. First of all, 60 English essay data processing, Swales to create the research space text mode as the evaluation criteria, respectively, on 60 papers to evaluate the mode of conformity, mainly from the perspective of the three-step process to consider whether the papers in accordance with Swales to create a research space. The author uses Swales to create the spatial discourse model of the research space by using the coincidence degree between the paper and Swales to create the research spatial discourse model, and sets the score as the variable $\mathrm{x}$. In addition, the teacher of college English writing class scored 60 papers according to their regular scoring mechanism, and set teacher's score of college students' English writing as variable $\mathrm{y}$ as an important indicator of college students' English writing ability and writing ability. After the two sets of scoring data are processed, the correlation coefficient calculation formula of Pearson correlation coefficient is used to calculate the correlation between the variable $\mathrm{x}$ and the variable $\mathrm{y}$, and then the Swales of the essay create the spatial discourse model of the study $\mathrm{x}$ and the score of the students' writing ability and writing ability $\mathrm{y}$. The correlation coefficient is 0.82 , the correlation coefficient is greater than 0.7 , indicating that there is a strong correlation between variables $\mathrm{x}$ and $\mathrm{y}$. There is also a strong correlation between Swales 'creation of research space texts and college students' English writing. Supported by the results of this calculation, college English writing teaching should be fully introduced Swales to create a research space discourse model, as an important discourse reference template in the process of student writing training, reasonable guide college students to improve their academic writing standards Improve the ability of college students to write English dissertations. At the same time, in the process of college English writing teaching, English teachers can analyze the sample text by instructing students to use Swales to create a research textbook, and take the step-by-step as the basis of the sample text to make students understand Swales' Mode in the realization of the purpose of communication purposes, and if the use of the model to guide the organization of the discourse structure of the thesis, so as to better meet the academic standards in the field of academic communication purposes. 


\section{Conclusion}

The existing researches on the creation of research space texts for swales are mostly concentrated in the dissertations of academic journals or master's doctorates, and seldom focus the research objects on college students' English writing. As a result, the undergraduate English writing courses in our country can not really play. The value and goal of writing training and education, many college students can only comprehend the normative writing of English dissertations when they continue to study for further study. In view of the above problems, this thesis focuses on the English writing class of college students, and quantitatively calculates the correlation coefficient between Swales 'creation of the research spatial discourse model and college students' English writing. The results show that there is a strong correlation between Swales 'creation of the research discourse model and college students' English writing It shows that swales' creation of a research space discourse model can serve as a template for the general academic discourse structure and is an important way for college students to standardize and improve their English writing.

\section{Acknowledgement}

This work was supported by an Empirical Study on the Impact of Hoey Problem-solving Discourse Patterns on College Students' English Writing in Hunan Philosophy and Social Science Fund Project (No. 11WLH11).

\section{References}

[1] Liu Hong, Yang Xinyi. According to the pace of the Chinese international education undergraduate teaching research thesis structure of the introduction [J]. Journal of Yunan Normal University (Teaching Chinese as a Foreign Language Edition, 2017,15 (02): 48 -56.

[2] Shi Jinhua, Chen Xin. Macroscopic Structure of Different Types of Abstracts in English Academic Articles: Commonness and Characteristics - A Case Study of Native Subjects and Non-natives in Computer Science [J] (14): 19-23.

[3] Huang Hui, Wang Shasha, Peng Yuna, Chai Haili. Genre Analysis of English Abstract in Business English Graduation Thesis - A Case Study of English Majors in a University in Jiangxi [J]. Linguistics, 2015 (02): 145-157.

[4] Wan Jingran, Song Yingying. Research on English abstracts of academic papers of Chinese medicine graduate students [J]. Examination Weekly, 2011 (73): 79-81.

[5] Zhang Shufang.Study on English Reading Teaching Based on Swales' Step-by-step Genre Analysis [J]. Journal of Hubei University of Economics (Humanities \& Social Sciences), 2011.8 (04): 190-191.

[6] Huang Ping, He Lingli. Comparison of Genre Structures of Experimental Papers in English and Chinese Academic Journals [J]. China ESP Research, 2011,2 (01): 22-27 +142.

[7] Sun Yinghui. Analysis of grammatical structure of "Preface" of Master's Thesis in English of Chinese students [J]. Chinese Foreign Languages, 2010,7 (06): 54-60 + 78.

[8] Wang Niya. Swales to create a research space discourse model and college students academic English writing thesis discourse structure analysis [J]. China Business Community (second half), 2008 (02): 221-222.

[9] You Liping. Analysis of Introduction to English Academic Articles by Using CARS Model of Swales [J]. Journal of Yunnan University of Finance and Economics (Social Sciences Edition), 2007 (02): 155-156. 